Article

\title{
Sustainability of Urban Functions: Dealing with Tourism Activity
}

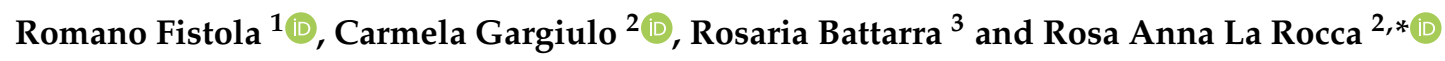 \\ 1 Department of Engineering, University of Sannio, 82100 Benevento, Italy; rfistola@unisannio.it \\ 2 Department of Civil, Architectural and Environmental Engineering, University of Naples Federico II, \\ 80125 Naples, Italy; gargiulo@unina.it \\ 3 Institute of Studies on Mediterranean Societies, National Research Council, 80134 Naples, Italy; \\ battarra@issm.cnr.it \\ * Correspondence: larocca@unina.it; Tel.: +39-0817685976
}

Received: 31 December 2018; Accepted: 14 February 2019; Published: 18 February 2019

check for updates

\begin{abstract}
This study aims to contribute to theoretical debate concerning urban planning, highlighting the need for a renewal of approaches and tools that could allow for the achievement of urban smartness. The concept of urban sustainability is evolving, also in relation to the incoming world of "smart cities," and it should be related to a systemic vision of the city. Referring to a systemic approach for the study of urban phenomena, sustainability can be considered as a target condition that cities have to achieve in order to contrast "urban entropy" and behave as smart cities. In this regard, our study starts from the premise that entropy is a negative state, which can affect the urban system in all its components. Among these components, the social subsystem can play a strategic role and some urban functions (such as the components of the functional subsystem) can be designated as "driving functions" that are able to lead the urban system towards a sustainable and smarter state of equilibrium. This equilibrium, though not static, can provide the efficiency of the system. Since tourism interests several aspects and sectors, it can be considered as one of the forces that, if properly controlled (i.e., by integrating it into the process of evolution of the system), would positively influence the evolution of the urban system. The application of the theoretical framework refers to the social (active) component of tourism, represented by the tourist flows that move inside the physical subsystem and can be traced through the data they disseminate by the use of their personal devices, with the aim of individuating the urban zones where the load of tourism concentrates. These areas can be marked as the ones urban planners and decision-makers have to first monitor in order to control the general state of the urban system equilibrium.
\end{abstract}

Keywords: systemic approach; urban entropy; urban tourism; urban smartness

\section{Introduction}

The present study deals with the concept of urban smartness meant as a set of conditions that can lead a city towards sustainable states of development. These conditions, among others, also refer to the ability of the city to monitor phenomena that occur, arise, develop, spread, and run out within the process of evolution of the city itself. Tourism will be considered as one of the forces, that if properly controlled (i.e., by integrating it in the process of evolution of the system), can positively influence the evolution of the urban system toward more sustainable and "smarter" development scenarios. Thus, tourism activity will be investigated as a component of the urban system, taking into account its complexity and pondering its aptitude to concentrate in urban areas that can be identified as sensible zones in which the interventions aimed at rationalizing the urban supply system could have a positive effect on the proper and efficient functioning of the whole urban system. 
Over the last decade, the concept of a "smart city" has gained attention as an approach propounding a model based on efficiency, resilience, and social equity. This model appears to reflect the targets of sustainability, though it seems to be far from reality when looking at people's current lifestyles (that are far from sustainable) [1].

The smart city concept, as well as the concept of sustainability, suggests the need to delineate a theoretical framework that, as of yet, is still lacking, mainly in the context of urban planning.

After a starting phase in which the word smartness was used as a synonym for technologies, the multiple definitions of smart city found in literature [2-7] agree with the acknowledgement that the social component plays a strategic role in the achievement of "urban smartness," meant as the will to pursue collective interests instead of individual objectives. This vision points out the active role that residents and city users, such as commuters, tourists, stakeholders, and other categories, must play in order to contribute to the process of evolution of the city itself $[8,9]$.

Beyond the definitions, the subject of smart city should be considered both as a research perspective to be investigated and as an opportunity to reflect on the basic concepts of urban development, also reconsidering the traditional tools of urban planning. What surely makes the "smart city" different from the other "city models" is the use of new information and communication technologies (ICTs) and, inevitably, in this transition, the highest level of expertise is needed to manage innovation, especially referring to the large amount of data that a smart city produces, in order to channel them toward sustainable uses of the city. These new competences should contribute to describe, interpret, and manage urban phenomena using technology as a powerful engine able to improve the smart dimension of a city [10], but, instead, technology is still used as an additional structure rather than an integrated component of the city. In this regard, a real paradox can be remarked considering the close connection between city and technology. A city can be seen also as the result of the application of technology to human action (nothing natural happens inside the cities). Nevertheless, despite the origins of technology, the digital revolution has radically changed the relationship between man and technology, modifying social interactions; this variation has happened faster than the city could coordinate its functional organization and its physical dimensions. Technology is essential for the smart city but, at the same time, the risk that it could turn into a social divider rather than an accelerator of progress is very high.

By considering these premises, this paper focuses on the functional planning of urban activities and attempts to demonstrate how big data originated from tourists acting in the physical system could support the decision-makers in defining priorities for intervention, individualizing areas of physical congestions, and functional overlapping (sensible urban areas). This paper, thus, is structured in three main parts: in the first part, the theoretical framework is sketched referring to the adoption of the systemic approach and the paradigm of complexity for studying urban phenomena [11]; in the second part, the topic of using big data produced inside the city from urban tourists is discussed; and the final part considers the tourist city of Naples as a case study, both to endorse the theoretical hypothesis and test the use of big data as a support tool to individualize the "sensible areas" within the urban system.

\section{Theoretical Background}

\subsection{Urban Entropy and the City as a Complex Dynamic and Spatial System}

This part of the paper considers the definition of the theoretical framework, taking full account of the objective of proposing the concept of "urban smartness," as being connected with the "condition" that cities can reach by reducing the production of urban entropy.

Many scholars [12-18] have argued that a city behaves as a complex and dynamic system, and as such, it can be studied as an open and complex geospatial system. Analogies between complex systems and cities allow for the adoption of some specific characteristics while studying urban phenomena. Among these characteristics, primary consideration should be given to: (a) the multiplicity of elements composing the complex system, (b) the multilayer structure of the complex system, (c) the adaptability 
of the system's dynamics, (d) the non-linearity of the relations within the system, (e) the non-linearity of the interactions that occur within the system, and (f) the property of self-organization of the complex systems.

By applying one of the properties of the complex systems (according to which, a system is part of a larger system and it, in turn, can be broken up into smaller subsystems), it is possible to consider the city (the main complex system) as composed by subsystems. Partitioning a system into subsystems has mostly to do with managing complexity, which refers to the non-linearity of the relations (a large number) among the elements of the system. The city, thus, can be thought of as a main complex system composed of three main subsystems (which, in turn, are complex): (1) physical subsystem; (2) functional subsystem; and (3) socio-perceptive subsystem, made of material and non-material elements as well as of static and dynamic components (Table 1).

Table 1. Static and dynamic components of the subsystems composing the city according to the adopted approach (source: authors' elaboration).

\begin{tabular}{cll}
\hline Subsystem & \multicolumn{1}{c}{ Static Component } & \multicolumn{1}{c}{ Dynamic Component } \\
\hline Physical & $\begin{array}{l}\text { Physical spaces: squares, } \\
\text { buildings, homes, etc. }\end{array}$ & $\begin{array}{l}\text { Physical channels of communication: streets, } \\
\text { mains, hydraulic infrastructure, technological } \\
\text { networks, etc. }\end{array}$ \\
\hline Functional & $\begin{array}{l}\text { Urban activities: administration, } \\
\text { education, culture, leisure, safety, } \\
\text { health, mobility, etc. }\end{array}$ & Communications and exchanges \\
\hline Socio-perceptive & $\begin{array}{l}\text { People living and enjoying the } \\
\text { cityPersonal images of the city }\end{array}$ & $\begin{array}{l}\text { Exchanges of information and } \\
\text { feelingsPersonal interpretations }\end{array}$ \\
\hline
\end{tabular}

Being complex systems, cities are also open systems, which evolve in space and time by changing their equilibrium and having interactions with the outside environment.

If the elements and the relationships within the urban subsystems are properly balanced, the city is in a sustainable dynamic state. Problems arise when one or more subsystems change the evolution trajectory and start to produce entropy $[19,20]$. The corrective actions to restore order have economic and social costs since resources are needed to re-drive the system toward conditions of efficiency; in doing this, the system produces entropy and loses energy.

The concept of entropy has its theoretical assumption in the second law of thermodynamics [21], which determines the variations of entropy of an isolated system but does not define its value. Within a system, an increase in entropy leads to a decrease in available energy [22]. When energy is no longer available, the system slides into the greatest level of disorder [23,24]; in this sense, entropy has been referred to as a measure of disorder. Unlike a closed system, an open system will not reach a static equilibrium but it will get a steady state characterized by continuous exchanges and changes. Open systems need to exchange materials and energy with their environment to keep themselves alive. This reaction, also known as "negentropy" $[25,26]$, has deeply changed the recent approach to the study of complexity. With the new vision of the open complex systems, some more characteristics have been outlined: the capacity of adaptation, the presence of chaotic attractor, the dissipative structure, self-organizational features, and the autopoietic ability. Taking these references into account, one of the goals of the present study consists in proposing a reflection on the application of entropy to the evolution of the urban system meant as a condition that contrasts sustainability in this development process.

Referring to the urban system, entropy (i.e., the production of energy that is no longer available) can be considered as a condition of scattered unconstructiveness (that produces negative effects within the system) representing an inappropriate use of the economic, social, and territorial resources required for its evolution. The system, thus, falls into a structural state of crisis and the urban entropy can be thought of as an unsustainable condition (entropy as opposed to sustainability). Being a dynamic system, the city evolves continuously in time and space, but as a complex system, it can enact a process of self-organization that can be defined as a "capability of adaptation," a widely investigated concept, 
especially in the field of systems science. Silvestrini [24] refers to the identification of the adaptability of a time-varying system [25-30]. In this regard, the present study assumes that, as a complex and dynamic system, the city has high levels of adaptation and its components change continuously and use endogenous processes to face external causes that can destabilize its equilibrium. When this occurs, the system is in a condition of entropy. Hence, the city smartness depends on its ability to mitigate the production of entropy. Can this target be gained through the individuation of some urban functions that play a leading role in the transition from entropy states to smarter states?

To answer this question, in the following paragraphs, tourism will be investigated as a particular urban function that, pursuant to its own cross-over nature, can foster a positive evolution of the urban system. Urban tourism is characterized by transversality and pervasivity. It is a transversal phenomenon as it interests, at the same time, several sectors (public and private) involved for its development. It is a pervasive phenomenon as it can be a sort of social practice that affects human behaviors, or a tourisming activity of everyday life [31].

\subsection{Tourism as an Urban Function in Tension between Entropy and Sustainability}

This part of the study assumes that tourism can be considered as a "leading urban function," capable of moving the urban system towards "states of smartness." In this transition, the physical, functional, and social components of the city are inevitably involved. The accomplishment of urban smartness is represented as a status of equilibrium between tourist demand and urban supply. Tourism in urban areas can be thought of as a system composed of a particular use of the urban system (demand side) and a supply side mainly composed of urban services and facilities designed to meet the needs and exigencies of a temporary urban population (tourists) that represents an additional load for the city.

Cities interested in tourism have to face a double issue due to the overlapping of two different types of demand using the city. On the one side, the specific "tourist demand" for services, infrastructures, and facilities, as well as attractions; on the other side, the traditional urban demand expressed by residents or by the daily and ordinary city users. In particular, the tourist demand (social component-anthropic subsystem) connects to a set of specific needs (Table 2) that urban systems must meet by making facilities (material component-physical subsystem) and services (immaterial component-functional subsystem) available. Many scholars have already highlighted that many of the urban services, spaces, and facilities have not been projected for tourist use [32-34]. This aspect, on the one hand, can affect the carrying capacity of the urban system, and on the other hand, can lead to conflicts between residents and visitors.

From Table 2, it can be observed that tourism concentrates in specific urban areas in which residents' use coexists with tourists' use, generating both physical congestion (traffic, noise, pollution, etc.) and functional overlapping that jeopardizes the organization of the entire urban system and its equilibrium.

Regarding these aspects, in the following paragraphs, this study considers tourism conceived as an urban leading function able to drive the city from unsustainability to smartness if well-planned and integrated within the urban process of evolution.

One of the main paradoxes in the connection between tourism and the city can be that today most of the cities aim to promote themselves as tourist destinations to increase their competitiveness, while tourism is seldom studied as an intrusive activity because of its indisputable positive economic effects (new employment, capital improvement, revenues, public and private investments, etc.). 
Table 2. Intersection between tourism and residents through the main physical structures.

\begin{tabular}{|c|c|c|c|c|c|c|c|c|c|}
\hline & \multicolumn{9}{|c|}{ Functional Subsystem: Activities } \\
\hline \multirow{30}{*}{  } & Main Tourist Needs & Amusing & Eating & Moving & Reaching & Relaxing & Security & Sleeping & Visiting \\
\hline & Accommodation Facilities & & & & & & & $\mathrm{T}$ & \\
\hline & Airports & & & & $T / R$ & & & & \\
\hline & Archeological areas & & & & & & & & $T$ \\
\hline & Auditorium & $T / R$ & & & & & & & \\
\hline & Bars & & $T / R$ & & & & & & \\
\hline & Bike sharing stations & & & $T / R$ & & & & & \\
\hline & Bus stations & & & $T / R$ & $\mathrm{~T} / \mathrm{R}$ & & & & \\
\hline & Car rental agencies & & & $\mathrm{T}$ & & & & & \\
\hline & Cinema & $T / \mathbb{R}$ & & & & & & & \\
\hline & Disco & $T / R$ & & & & & & & \\
\hline & Embassy & & & & & & $T$ & & \\
\hline & Fast food; Bars & & $T / R$ & & & & & & \\
\hline & Historical, Botanical Garden & & & & & $T / R$ & & & $T / R$ \\
\hline & Local Public Transport & & & $T / R$ & & & & & \\
\hline & Monuments & & & & & & & & $T / R$ \\
\hline & Motorways & & & & $T / R$ & & & & \\
\hline & Museums & & & & & & & & $T / R$ \\
\hline & Night club & $T / R$ & & & & & & & \\
\hline & Panoramic points & & & & & & & & $T / R$ \\
\hline & Police and Order Offices & & & & & & $T / R$ & & \\
\hline & Ports & & & & $T / R$ & & & & \\
\hline & Railways stations & & & $T / R$ & $T / R$ & & & & \\
\hline & Restaurants & & $T / R$ & & & & & & \\
\hline & Shopping center & & & & & $T / R$ & & & \\
\hline & Subway stations & & & $T / R$ & $T / R$ & & & & \\
\hline & Taxies & & & $T / R$ & $T / R$ & & & & \\
\hline & Theatre & $T / R$ & & & & & & & \\
\hline & Thermal and Wellness Center & $T / R$ & & & & $T / R$ & & & \\
\hline & Tourist Information Offices & $\mathrm{T}$ & $\mathbf{T}$ & $T$ & $\mathbf{T}$ & & & $\mathrm{T}$ & $T$ \\
\hline
\end{tabular}

Notes: T: Tourist Use; T/R: Mixed Use (Tourists and Residents).

As a matter of fact, tourism has a key role in socio-economic progress: according to the World Tourism Organization, about 9\% of the gross domestic product (GDP) comes from tourist activities (direct, indirect, and induced), and tourist arrivals worldwide are expected to increase by $3.3 \%$ a year to reach 1.8 billion by 2030 [35]. Actually, in the history of tourism, cities have always been favorite destinations. A city represents the physical place in which the "tourist desire" is accomplished. Urban tourism is generated from this legacy, becoming both an object of scientific research $[36,37]$ and a target for urban transformation. In recent years, the focus of urban policies has converged towards the tourism development as one of the main opportunities to lift territorial economies. This possibility makes the city an exclusive "sensible" tourist destination. Sensibility refers to the need of managing the tourist flows in the city in order to reduce the negative impacts on the urban system's evolution [38,39]. The need to manage urban tourism has also been discussed in scientific literature [40-44], though a lack of interest in considering the management of this phenomenon as part of the city planning, the transport design, or the policies for urban regeneration (where most of the local tourism strategies take place) still exists. Although many scholars highlight the need to develop policies according to a holistic approach [45], up to now, the main focus has been on the promotion of tourism regardless of the consequences that a not well-planned development could weaken the fruition of the territorial resources. The role of urban planning (the pursuit of an order via a plan) concerning the tourist use of 
a city should be addressed toward an integration between urban marketing and governance goals, and it must take into account that tourist cities as tourist destinations evolve and behave as complex dynamic (open) systems.

\subsection{Tourism as a Driving Urban Function}

A systemic approach and the paradigm of complexity allows for the proposal of studying the relationship between tourism and the city according to a different way of thinking. This approach makes it possible to consider the connections and simultaneous interactions that could occur among each urban subsystem and with the entire system. Thus, if a single element changes, it inevitably produces an alteration of the status of the whole subsystem, and this, in turn, modifies other subsystems, and so forth like a domino chain. The state of structural crisis occurs when during this chain effect, the production of entropy is amplified, affecting subsystems and hence the entire urban system. On the other hand, when the system lays in a balanced state, even if not static at all, it is able to control the production of entropy such that it can evolve along a controlled sustainable trajectory. When an endogenous malfunction occurs within the subsystem generating entropy, the system itself collapses beyond repair (Figure 1).

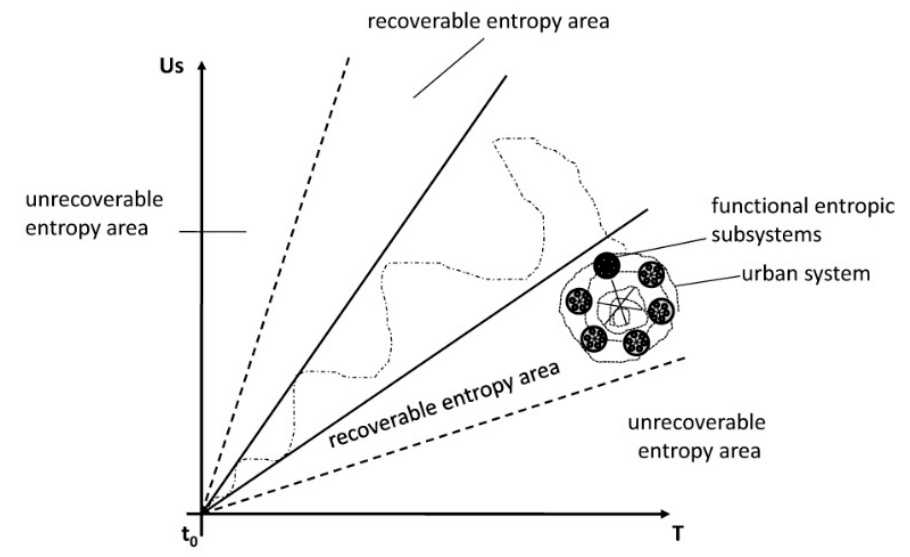

Figure 1. The functional subsystem affected by entropy drives the entire urban system towards the entropy zones (authors' elaboration).

With particular reference to the functional subsystem, it is possible to observe that activities are the driving forces playing the double role of being elements of positive propulsion when acting appropriately, while becoming "entropic generators" if affected by anomalies. In this regard, considering tourism in its complexity as urban function $[36,38,39,46]$, it is possible to observe its double role in this performance of the system.

When tourism oversteps the carrying capacity of the entire urban system, it generates entropic chains that gradually lead the city toward an unsustainable state of evolution. The tourism paradox is found in the fact that tourists are both the inducement and the deterrent for the success/failure of a "destination." The "overtourism" [40] concept shows that in a city, tourism has to be managed and planned to reduce the impacts deriving from the not well-balanced supply-demand system. In this case, tourists can be observed as a particular typology of users defined as "entropic temporary residents" [36], and as such, they represent the part of urban demand to be planned and monitored.

In view of the above, this study considers tourism as one of the urban activities and does not approach the study of the tourism-city relationship from the destination management perspective. Rather, by assuming the logic of the complex system, it aims to demonstrate that (if considered as a component of the urban system) the role of tourism can be fundamental to improve urban policies targeted toward sustainability objectives. For this part of the research, the authors supposed that the study of tourist flows inside the city could represent a first step toward the integration of methods and the modernization of tools of urban planning. In other words, at the present state of the research, 
it has been deemed that the dynamic component of tourism inside the city (the flows of movement) would have been more significant for the goals of the study itself. Further research developments will be oriented toward a deeper analysis of the consistence and typology of tourist flows.

\section{The Active Role of Tourists inside the Urban System}

This section aims at investigating the possibility of using data generated from tourists during their visit and particularly focuses on the transformations that occurred in the social subsystem due to the use of technologies.

It can be observed that citizens' behaviors have deeply changed and they are rapidly modifying their habits by introducing new technologies into their daily lives. The number of people connected to the web through a mobile device is expected to be about five billion by the end of the current year [47], which is particularly significant considering that the world's population is about seven and half billion people. In Italy, for instance, there are at present about 95 million connected devices, and this number is expected to rise to about 160 million by 2021. In this regard, it is possible to state that the technological interaction has taken over a significant portion of the dynamics of human relationships and that a "new" technological revolution is affecting the social component of the urban system.

The main changes concern the switch from a "passive role" to an "active role" played by citizens and city users as they become producers and consumers of information and data at the same time. Such a transition also involves tourism, radically modifying the way tourists plan, live, and share their tourist experiences. The so-called big data phenomenon (meant as the product of information generated by people living and using the city through their personal devices that inevitably influence their everyday actions) is characterizing the relationship between people and urban spaces and is giving researchers the chance to observe some occurrences while they are happening (the "real time").

What is more important for the objective of this section of the paper is the possibility to use big data for the analysis of tourism as an urban phenomenon, bypassing the traditional datasets, which are rarely available and updated [39]. The main difficulties in studying urban tourism consist in the impracticality of assessing tourist flows that concentrate in the city, apart from the number of tourist overnight stays in traditional accommodations. This condition does not allow researchers to consider the different flows that tourism activates inside the city, and makes it difficult for decision-makers to define appropriate management policies of the phenomenon.

In the context of these issues, the use of big data as a revolutionary tool has gained significance, especially in the tourism industry. Actually, big data are used within the marketing strategies to investigate the interactions between users' behaviors and their satisfaction level in order to improve the quality of the supply-side and reduce costs. As previously stated, the use of big data is especially relevant for tourism companies, since the "traceability" of users becomes fundamental, both to improve the tourist market and optimize the supply, in order to adapt to the complexity of the demand-side. The Italian Digital Tourism Laboratory, founded in 2014 by the Ministry of Tourism, highlighted that tourism is more and more involved in the use of digital technologies. In Italy, about $91 \%$ of tourists planned their holidays and travel by using the Internet, and about $42 \%$ used mobile devices for moving and visiting destinations. The constant use of technologies is producing a huge amount of information (the big data) that needs high levels of specialization to be interpreted and effectively useful, especially to analyze the relations between tourists and places, according to an urban planning perspective.

In the context of these considerations, the following part of the paper deals with the attempt to formalize the use of data produced by tourists while visiting a city in order to identify the urban zones in which tourism flows concentrate. The objective is to detect urban sensible areas that need priority interventions to improve the livability of the city for both visitors and inhabitants. The methodological premises have been implemented for the city of Naples, considered as an interesting case for both its re-emergent role as a tourist city and its intrinsic complexity. 


\section{Study Design: Method and Phases}

In order to investigate tourist flows and their concentration, data deriving from TripAdvisor's (https:/ / www.tripadvisor.it/TripAdvisorInsights) massive data sets seemed to be the most reliable in the tourism sector, both for their relevance (320 million reviews and opinions referring to tourism experiences in 2017) and dissemination (about 47 countries in the world in 2017). The TripAdvisor platform works according to the same principle of social networks: users provide contributions to create the content. In this respect, TripAdvisor can be considered as a social network that integrates the phase of travel planning by supporting users in their decision making. Besides, the possibility to integrate TripAdvisor with Facebook makes it the most pervasive system for sharing the opinions currently available. Actually, such pervasiveness could limit the reliability of information, as well as that of the contents. Nevertheless, according to a survey conducted by PhoCusWright $87 \%$ of the sample states that consulting TripAdvisor helps improve users' final decision to travel to a destination or not [48].

Despite recognizing the limits that a survey exclusively based on a social network entails, within this study, the large amount of information stored on the TripAdvisor platform has been considered as a resource comparable to big data and useful for the implementation of algorithms supporting analysis regarding dynamics of urban phenomena, such as tourism. In this framework, this part of the study presents an initial experimental application by using the TripAdvisor platform to define where tourist flows concentrate and, thus, to individuate tourist attractive zones within the urban system. Identification of the most congested and overcrowded urban areas can represent a tool for urban planners to determine a hierarchy of interventions aimed at restoring conditions for urban equilibrium.

The analysis was conducted according to three main phases:

1. collection and organization of data;

2. export and geo-referencing of data using GIS technologies;

3. development of spatial analysis.

Phase 1: Collection and Organization of Data

This first phase was focused on data mining related to the pursuit of the research objectives. The first step concerned the use of TripAdvisor for the collection of raw data in HTML format. The choice of User Generating Content (UGC) data in this specific case concerns the possibility of using such data in relation to the placement of tourists/visitors within specific areas beyond the content of the reviews (object, instead of significant analyses that fell outside the objectives of this research segment). Therefore, the analyses carried out concerned UGC data from the largest review website available today [49]. The use of such data is particularly significant and partly innovative in the study of spatial analysis of user flows within the city and in the definition of their mobility. Much more widespread are the applications of sentiment analysis, aimed at defining preferences and the quality of visitors' experiences.

As already highlighted, the analysis focused on the location of the reviews rather than on their contents. To this end, a preliminary phase that involved the selection of significant information and their subsequent organization into a database was necessary. Within the TripAdvisor portal, users release information on three main service categories: (1) POI (points of interest), or the attractions; (2) restaurants; and (3) accommodations. Among the three categories, the data of the first and third categories were identified as significant for the purpose of this work. The second category, despite being relevant within the tourist supply, is too widespread in the area and very promiscuous compared to its specific tourist use.

The data skimming phase was carried out through the use of a crawler (Web Scraper since its scope was quantitative rather than limited to content analysis. However, the content of the text was used to select the reviews according to their significance, referring to the category of interest. The next phase involved the construction of clusters for spatial analysis aimed at defining the intensity of tourist visits to a given place (actors/spaces relationship). 
Phase 2: Export and Geo-Referencing of Data using GIS Technologies

The use of GIS was the focus of this second phase. The raw data selected and organized in the database were imported into the GIS environment to perform operations of information geolocation. The users' reviews were considered as the actual trace of their presence in the place they reviewed. Therefore, it was assumed that the reviews corresponded to the number of visitors of the chosen tourist destination and to its attractive elements. This hypothesis was based on the existence of a relationship between the location of a tourist accommodation and the number of reviews, which proves the intensity of use of the structure itself.

Phase 3: Density Analysis

Density analysis is based on the distance and neighborhood principle. In theory, a significant number of points belonging to a specific cluster must be contained within a neighborhood measure, defined by a given radius that the detector can assign according to the observed phenomenon. In this phase, the elaborations were carried out through spatial analyses conducted in the GIS environment (it was decided that QGIS software was to be used). In particular, we adopted a double analysis method that referred to the use of hotspot analysis tools through the kernel density estimation (KDE), a non-parametric method widely applied in territorial analysis [50,51]. This type of analysis makes it possible to identify the areas of greatest concentration of the phenomenon under examination (hot areas) and those where the phenomenon is null or not very relevant (cold areas). The parameters and the relations among them are fundamental in defining the density mapping, and are regulated by the following expression:

$$
\lambda(\mathrm{s})=\sum_{i=1}^{n} \frac{1}{\tau^{2}} k\left(\frac{s-s_{i}}{\tau}\right)
$$

where

$\lambda(s)=$ estimate of the intensity of points distribution

$k=$ kernel function

$s=$ measuring point of density estimation

$s_{i}=$ ith point of analysis

$\tau=$ bandwidth

Equation (1) considers that for each point " $s$ " located in the study area, the intensity of concentration of " $s_{i}$ " points is measured, in relation to a bandwidth " $\tau$ ". Such an index allows for the visualization of the functional urban environment by means of a density surface related to the physical areas of the urban system in which activities concentrate.

\section{The Case Study: Exploring the Tourist City of Naples}

\subsection{The "Tourist City" of Naples}

Tourist cities have been normally defined by urban geographers as referred to three main types:

- $\quad$ resort city created expressly for tourism;

- tourist-historical cities with a defined identity;

- converted cities that originally were not suited to host tourism, but to regenerate their economies they had to adapt some urban spaces to this specific function [52].

Regarding the aforementioned categories, it is possible to add a fourth type that refers to the "tourist city" as a part of the city itself, sometimes geographically identifiable as a sort of "sub-city." Normally, these sub-cities coincide with the inner city in which historical monuments concentrate, but in spite of their historical origins, they have gradually changed into "representative urban areas" in which tourist services have replaced urban activities. These areas fall within the concept of "sensible 
areas" of the urban system in which urban policies have to focus not exclusively on improving their tourist attractiveness but especially on increasing their urban livability, both for tourists and residents.

In this regard, the tourist city is a city inside the city in which the elements of the urban supply system (mainly devoted to tourist use) concentrate. The tourist urban supply is an articulated system composed of two main subsystems: on the one side, the historical heritage representing the "hard core" of the supply system; on the other side, the variety of ancillary services for tourism activities (from accommodation to "where to eat," entertainment, visits, and so on) representing the "soft core" of the urban supply. The localization of these structures inside the urban context can help define the "tourist city" as it has been outlined in this study.

In a previous study, La Rocca [46] individuated the "tourist city of Naples" and elaborated a city zoning based on the level of attraction (Figure 2) defined using the elements of the supply side that were present at the time. The urban supply system for a tourism use referred to three main categories: (a) the attractive poles (museum, historical sites, historical buildings, environmental areas, historical parks, etc.); (b) accommodation facilities; and (c) public local transport supply, particularly referring to subway lines (Figures 3-5).



Figure 2. The procedure for the definition of the tourist city as applied to Naples (authors' elaboration).
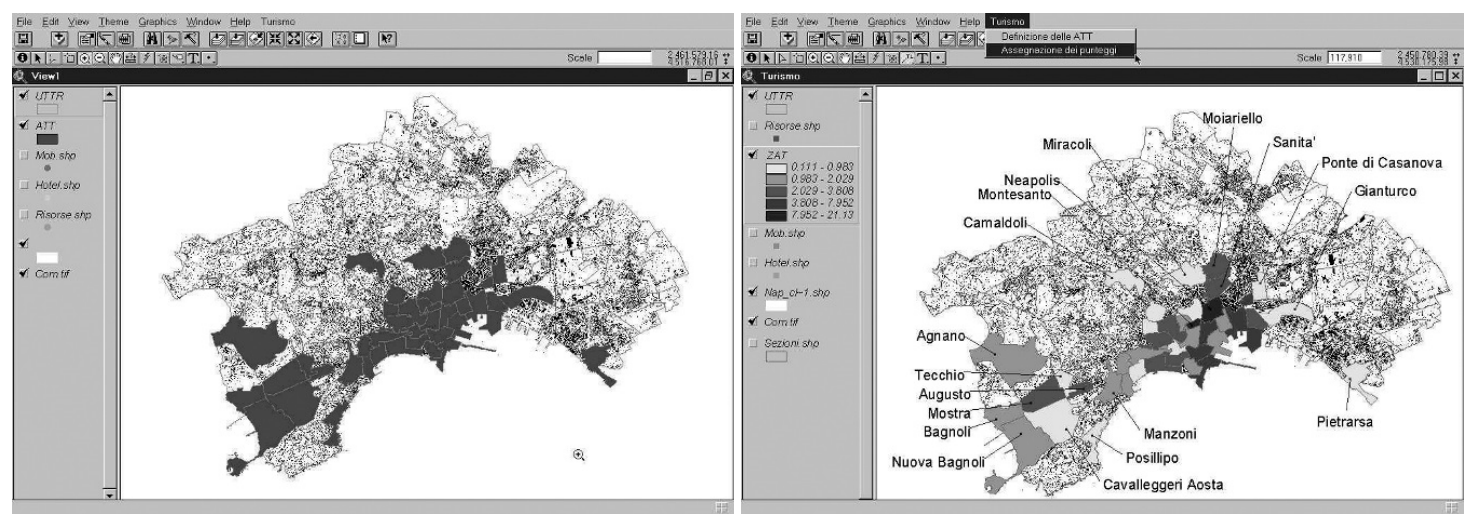

Figure 3. The tourist city of Naples as a product of the implementation of the procedure illustrated in Figure 2. 




Figure 4. Supply-side elements in Naples in 2003 (authors' elaboration).



Figure 5. A zoning map of the tourist city of Naples according to the attractiveness index calculated in La Rocca [46]. The red area defines a unique central zone corresponding to the inner city, a recognized United Nations Educational, Scientific and Cultural Organization (UNESCO) World Heritage site in 1995 (authors' elaboration).

The analyses carried out were based on the definition of the supply-side elements with reference to three prevailing categories: accommodation, attractiveness, and mobility. The categorization of the areas had been elaborated in the GIS environment under the condition of the simultaneous presence of the three elements above mentioned in the areas of attraction. The tools used did not refer with respect to the components of the demand-side since the available data were not accessible for security 
and privacy reasons. Thus, the limit of the research essentially consisted in the lack of comparability between the elements of the physical system (substantially rigid) and those of the functional and social system (characterized, instead, by a rapid evolution in behavior and means of communication).

Hence, the need to resume the results of the analysis carried out by using more up-to-date tools mainly focused on the behavioral component in order to simulate the distribution of the tourist load within the city, and consequently, to make appropriate choices for monitoring and managing these flows. Interestingly, the elements of the supply system that constitute the "fixed" component (that is, the physical elements representative of the city's history and culture) were not modified (as probably foreseeable), as well as the rail public transport supply considered in the previous analysis, except for some new stations on the hill subway line (now Line 1). On the other hand, the elements of the supply related to accommodation facilities, which in the period under review recorded a decisive increase $(+7.3 \%)$, and represented the variable component. The figure becomes even more significant considering the development of the hospitality industry with the introduction of new categories of accommodation facilities (i.e., Airbnb) (Figures 6 and 7).

Once again, particular attention is drawn to the difficulty in finding reliable data to provide a real assessment of the current accommodation supply. Even the Airbnb data manager recognizes the unofficial structures and the non-traceability of data. Beyond the merely statistical issues, it is relevant to point out that the elements relating to the supply system and affecting the receptive component show the most significant increase over the period considered. However, the density of tourist accommodations is concentrated in the central areas of the city.

Therefore, the physical space of the tourist city of Naples does not change significantly, unlike its functional components that register a strong increase in density values (relationship between activity and territory). Thus, the subsequent phase of the work was oriented toward the use of new analysis tools for data updates in order to highlight the urban areas where the tourist load was concentrated and identify the "sensible areas" within the tourist city.

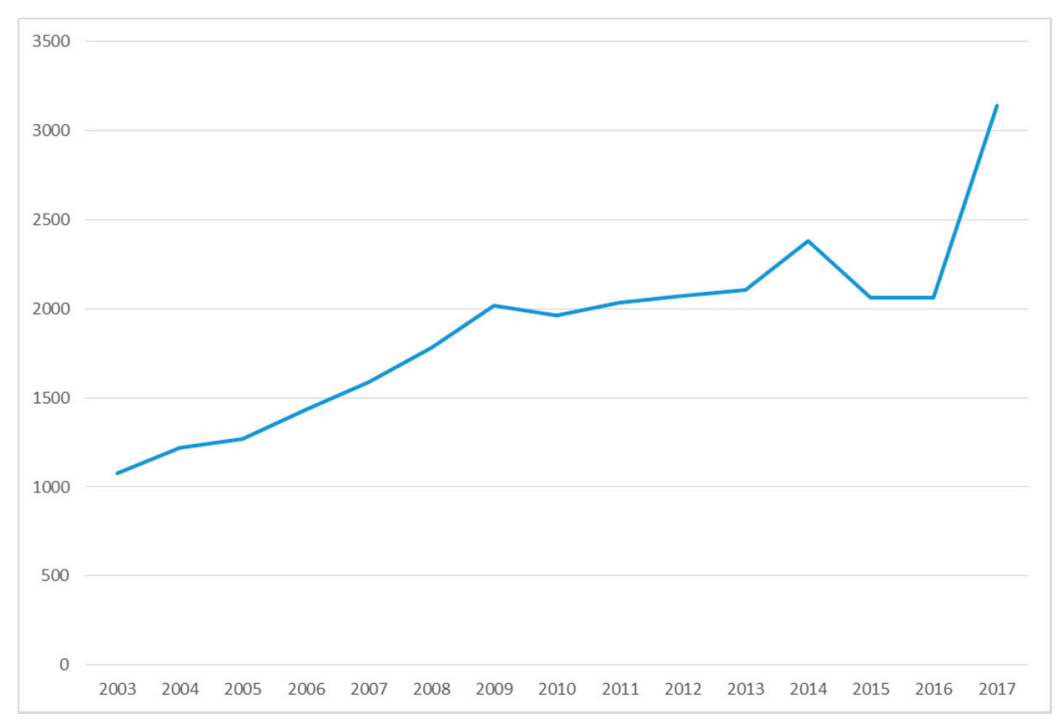

Figure 6. Total tourist accommodation facilities (hotels and B\&B) in Naples from 2003 to 2017 (authors' elaboration on National Institute of Statistic ISTAT [53]). 

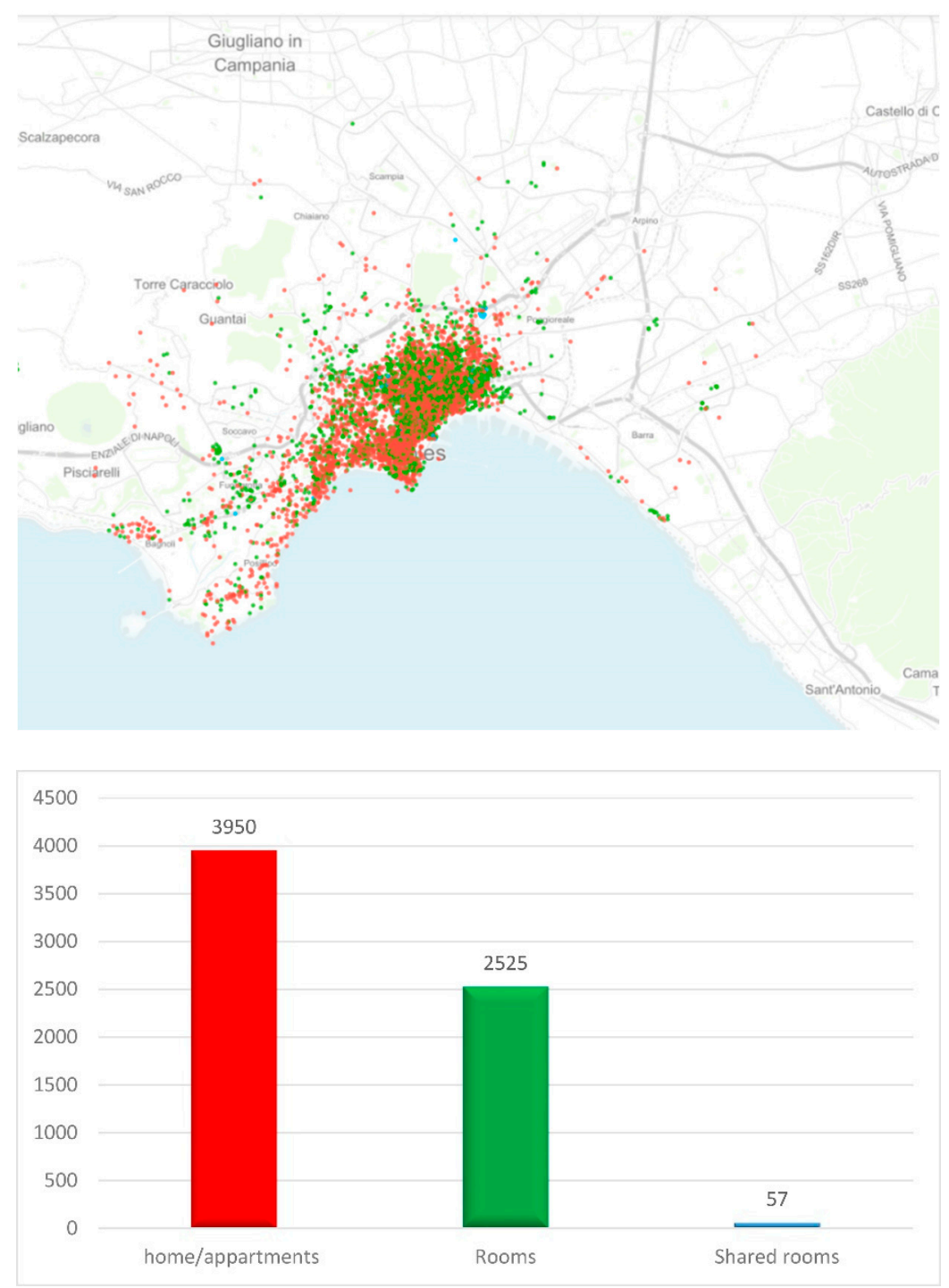

Figure 7. Airbnb in Naples in 2017 (source Inside Airbnb, accessed 10th October 2018; authors' elaboration using Airbnb data).

\subsection{Exploring the "Urban Tourist Sensible" Areas in Naples through UGC}

Tourist sensible areas are those urban zones where the overload of tourist flows occur, jeopardizing the livability of the city. These zones have been identified using data mining techniques, based on the most common social web-based platforms collecting "tourism experiences." Before delving into the phases of our analysis, some considerations about how the use of ICTs applied to a social dimension (social media) contributes to the evolution of tourism activity can be useful for the topic of this part of the research (even though the transformation of the tourism industry is not its focus).

The use of social media for tourism is radically changing the way tourists plan, spend, and live their trips. One of the fundamental changes generated by technologies is the shift of the customers' role from passive to active, from consumers of services to co-creators of information [54].

Sigala [55] indicates the main functions for the role of technologies in tourism (p. 152), two of which seem to be particularly relevant for the subject of this section:

- market intelligence sources for collecting, storing, analyzing, sharing, visualizing, and interpreting big data (characterized by volume, variety, velocity, veracity, and value); 
- co-creation platform (i.e., review websites, wiki-based tourism guides, and peer-to-peer marketplaces) empowering and providing space, functionality, and connectivity to all tourism actors who actively engage and participate in value co-creation.

The first one seemed to be much closer to the aim of this part of the paper in relation to the opportunities to investigate the tourism activity through the traces left within the destination chosen. The second one seemed to refer particularly to the use of web platforms to share opinions about the quality of services, provide hotel reviews, and describe how to enjoy a tourist attraction system. TravBuddy.com, TripAdvisor, Travellerspoint, Wayn, and Booking are some examples of the most common websites used in the era of "smart tourism," characterized by a large amount of digital traces. While recognizing the issue raised by the smart tourism production of information and data not yet structured [56], the aim of this study refers to the attempt of relating the digital traces left by visitors to the identification of the tourist city using the demand-side preferences. The analysis of UGC (user-generated content) allows for the application of an innovative way to consider tourist flows, mainly for three reasons: data are directly produced by users; are more rapidly available than traditional data; and finally and most importantly, their use allows less expensive analysis, assuring the same reliability as questionnaires or GPS analysis.

The application to the case of Naples has been oriented toward a dual purpose: on the one hand, for a comparison between the previous analyses [46], especially with reference to the area of the "tourist city" of Naples; on the other, for the experimentation of new methodologies for the physical representation of an urban activity (the tourist one) with high impact for the functioning and efficiency of the urban system. The ultimate aim of this experimentation consists in the development of a useful tool for supporting a public decision-maker's definition of tools and policies of urban transformation in the most "sensible" areas (by concentrating and/or overlapping user flows) within the urban system.

The role of Naples as a city of tourist attraction within the national and international scene is the basis of this work, supported by the official traditional data elaborated by ISTAT (National Institute of Statistic) and Eurostat about the tourism flows in the last decade. This condition strengthens the case study significance in relation to the objectives of the entire work, which assumes that the tourist activity phenomenon has the potential of stressing the equilibrium of a complex urban system.

The development of the experimentation refers to the three main phases described above and focuses on the data relating to attractions and accommodation facilities.

Analysis refers to two main categories: points of interest (that act as attractors of urban tourist flows) and accommodations (referring to the number of hotels and B\&Bs in Naples in the period from March 2017 to April 2018). The information extracted for each item of the macrocategories (Table 3 and Figure 8) especially refers to:

- $\quad$ personal information (name, address);

- number of reviews posted in the last year;

- $\quad$ types of tourists (families, couples, solo-travelers);

- motivation of the visits (business, visit friends, leisure, etc.).

The second phase (export and georeference of data using GIS technologies) was carried out through a geocoding technique for multiple addresses. The adoption of a plugin (Mmqgis) of the QGis software allowed for the georeferencing of each element composing the chain of the tourist urban supply, particularly referring to the points of interests and accommodation facilities, as structured in Table 3.

As mapped in Figure 12, the elements of the urban tourist supply chain are mainly concentrated in the inner city. Few elements are concentrated in external areas, following two opposite directions: on the eastern side, toward the environmental system of Vesuvio; and on the western side, where elements distribute towards the residential area of Fuorigrotta (characterized by the presence of the large Bagnoli brownfield site, ex-Italsider) with its pivotal role between the city and the Phlegrean Fields volcanic site. 
Table 3. The table shows the categories in TripAdvisor clustered into two macrocategories.

\begin{tabular}{|c|c|c|c|}
\hline Macrocategories & TripAdvisor Categories & $\begin{array}{c}\text { Number of Records for } \\
\text { Categories }\end{array}$ & \\
\hline \multirow{28}{*}{ Point of Interest } & Arenas \& stadiums & 2 & \\
\hline & Seaward & 3 & \\
\hline & Lookouts & 1 & \\
\hline & Castles & 3 & \\
\hline & Caverns and cave & 1 & \\
\hline & Churches \& Cathedrals & 71 & \\
\hline & Historic cemeteries & 3 & \\
\hline & Architectural Buildings & 33 & \\
\hline & Government Buildings & 3 & \\
\hline & Fountains & 14 & \\
\hline & Points of Interest \& Landmarks & 58 & \\
\hline & Monuments \& Statues & 7 & \\
\hline & Antique shops & 1 & \\
\hline & Historic Walking Areas & 5 & \\
\hline & Neighbourhood & 6 & \\
\hline & Ancient Ruins & 9 & \\
\hline & Mysterious Sites & 1 & \\
\hline & Sacred \& Religious Sites & 19 & \\
\hline & Historic Sites & 20 & \\
\hline & Observation Decks \& Towers & 1 & \\
\hline & Art Galleries & 20 & \\
\hline & Art Museums & 14 & \\
\hline & Science Museums & 2 & \\
\hline & Speciality Museums & 32 & \\
\hline & Natural History Museums & 1 & \\
\hline & History Museums & 6 & \\
\hline & Observatories \& Planetariums & 1 & \\
\hline & & 337 & $\begin{array}{l}\text { Total number of records } \\
\text { for macrocategory POI }\end{array}$ \\
\hline \multirow{4}{*}{$\begin{array}{l}\text { Accommodation } \\
\text { Facilities (AF) }\end{array}$} & Hotel & 162 & \\
\hline & Bed \& breakfast & 576 & \\
\hline & & 738 & $\begin{array}{l}\text { Total number of records } \\
\text { for macrocategory AF }\end{array}$ \\
\hline & & 1075 & Total number of records \\
\hline
\end{tabular}

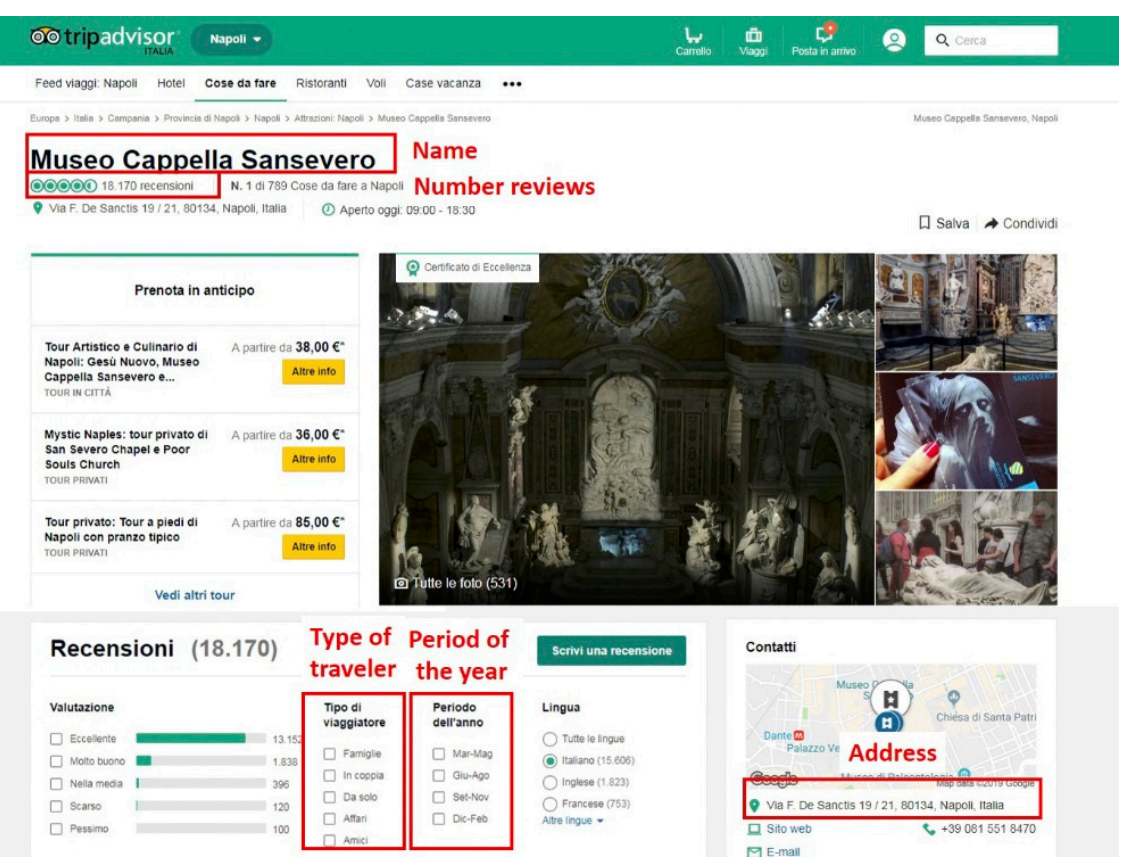

Figure 8. The picture shows an example applied to the Chapel of San Severo, one of the most famous points of interest within the tourist city of Naples. The red boxes underline the data mining information collected from TripAdvisor. 
Concerning the third phase (spatial analysis), some preliminary conditions have been fixed. Considering both the characteristics of the distribution of the urban supply elements, the territorial orography and the extension of the inner city, the bandwidth (bw) was set at $400 \mathrm{~m}$ in order to map the kernel density estimation as this distance can be comfortably walkable in about five minutes at a speed of $1.3 \mathrm{~m} / \mathrm{s}$. This distance, which refers to the rules of the Highway Code, was established considering all the pedestrian paths existing within the Historical Center of Naples to reach the place of interest. In addition to testing the distance as effectively passable, KDE applications show that the size of the bandwidths controls how smooth the resultant surface is and a small bandwidth will give a spiky surface as a result, which is very difficult to control and describe.

In order to estimate the value of density, the kernel method refers to the definition of a grid that acts as territorial base of analysis. The definition of the grid is another basic aspect of the spatial analysis because it can hardly modify the significance level of the results. The grid size was calculated to be $10 \mathrm{~m}$ in relation to both the scale representation of the phenomenon and to literature experiences [56-60], showing that the smaller the grid, the better the results will fit the phenomenon observed. The value of density was calculated by overlapping the grid with the punctual distribution of the elements of the supply chains, as mapped in Figure 9.

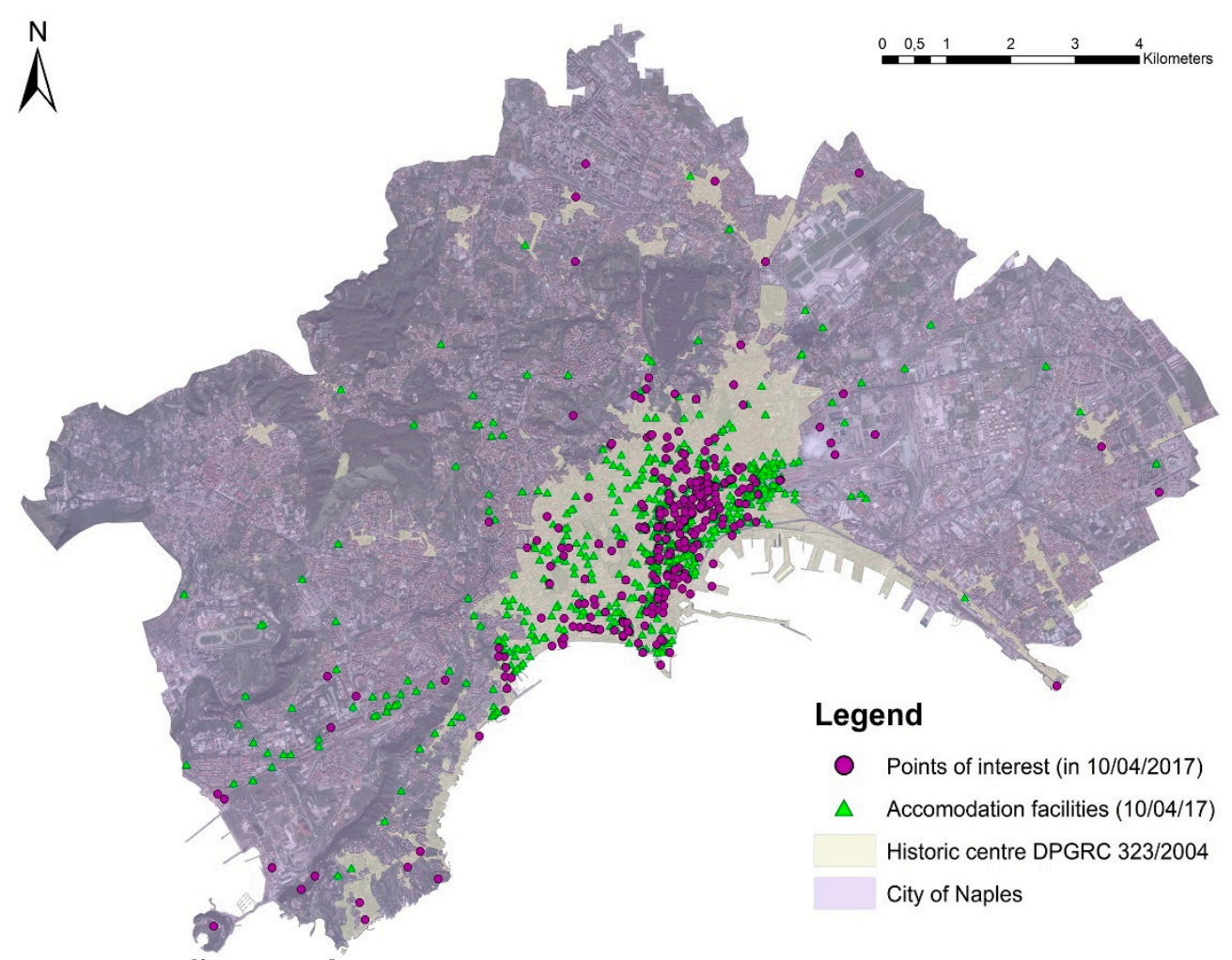

Figure 9. Geocoding for multiple addresses of 337 points of interest (POI) and 738 accommodation facilities in Naples.

In the analysis of TripAdvisor data, it was considered that the number of reviews could correspond to the number of visitors according to a proportion related to the type of tourists (families, couples, solo-travelers). Table 4 shows an example of the proportion applied to convert the number of reviews into a corresponding number of visitors. The example refers to the Chapel of San Severo, (Figure 8 and Table 4) considered as one of the most significant for the processing of the present analysis. 
Table 4. Multiplication coefficient for converting the number of reviews into visitors, referring to the "Museum of the Chapel of San Severo" in the inner city of Naples.

\begin{tabular}{ccccc}
\hline Type of Traveler & $\begin{array}{c}\text { Number of } \\
\text { Reviews }\end{array}$ & $\begin{array}{c}\text { Multiplication } \\
\text { Coefficient }\end{array}$ & $\begin{array}{c}\text { Number of } \\
\text { Estimated Visitors }\end{array}$ & $\begin{array}{c}\text { Total Number of Reviews } \\
\text { Considered in the Kernel Analysis }\end{array}$ \\
\hline Families & 1868 & 4 & 7472 & 15,254 \\
Couples & 3563 & 2 & 7126 & \\
Solo Travelers & 656 & 1 & 656 & \\
\hline
\end{tabular}

The results of the kernel density estimation have been mapped referring to the urban system of Naples. Considering the two macrocategories, the value of density concerned two types of tourist flows: visitors and guests. Figure 10 particularly illustrates the map of density referring to the number of "visitors," meant as the tourist flows that concentrate in the points of interest identified above (Figure 9), while Figure 11 shows the map of density for "guests," corresponding to the number of presences registered in the accommodation facilities already identified (Figure 9). The final results of the total density estimation of tourism flows in Naples have been showed in Figure 12. The levels of polarization have been classified by using the natural breaks (Jenks) method, articulated in four classes according to a grey to red color scheme to point out highs (red) and lows (grey) of point pattern densities. As expected, "visitors" flows concentrated inside the inner city where the most known attractions are located. Concerning "guests," they concentrated both in the areas close to the historical center and in those strategically close to the "access points" to the city (the central railway station on the east side, for example). It is very interesting to note how "the tourist city of Naples" has remained virtually unchanged and concentrated in the central areas of the city.



Figure 10. Map of the density estimation for "visitors" flows in Naples (kernel density, cs = 10; bw =400). 


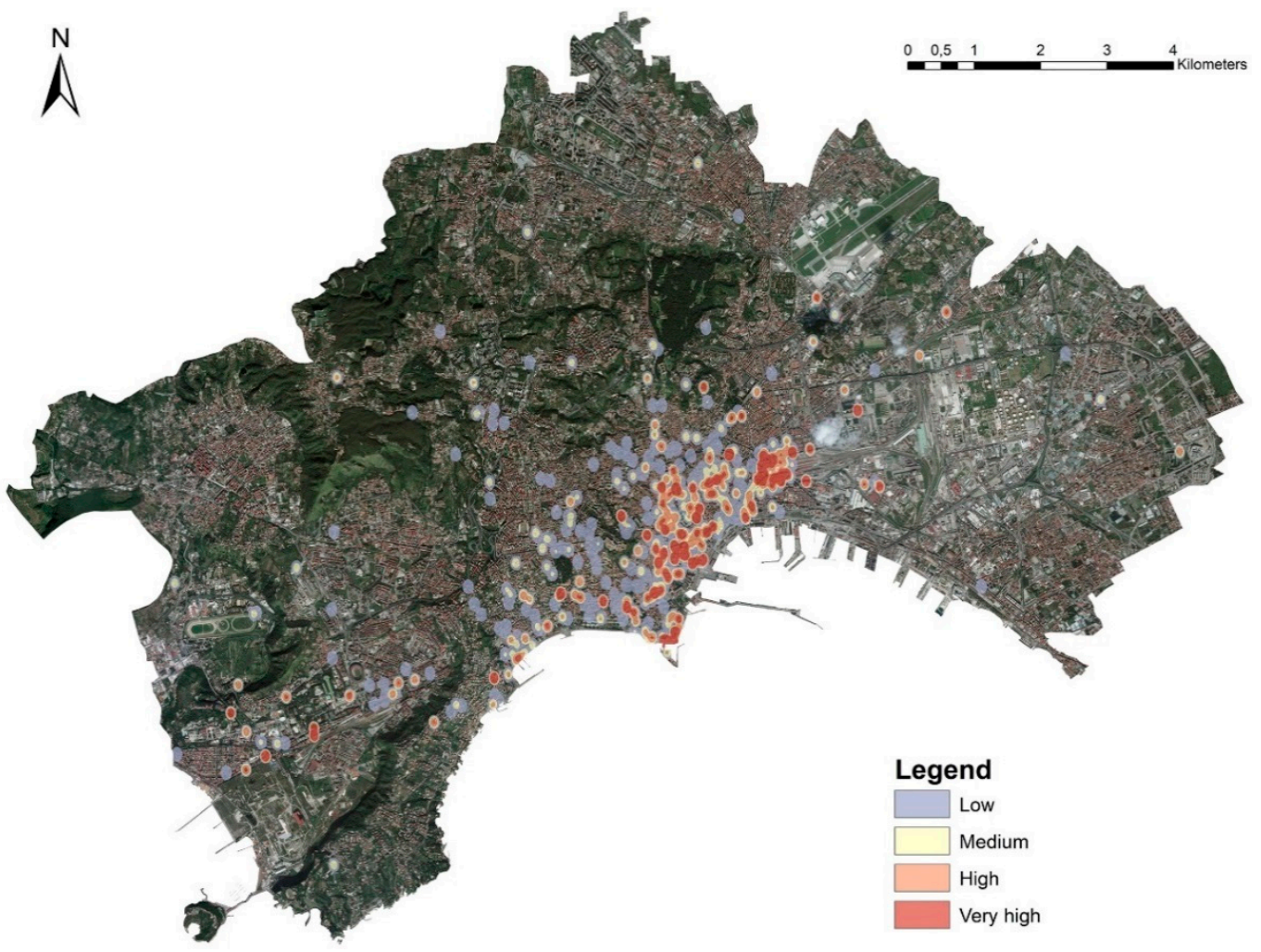

Figure 11. Map of the density estimation for the "guests" flows in Naples (kernel density, cs =10; bw = 400).

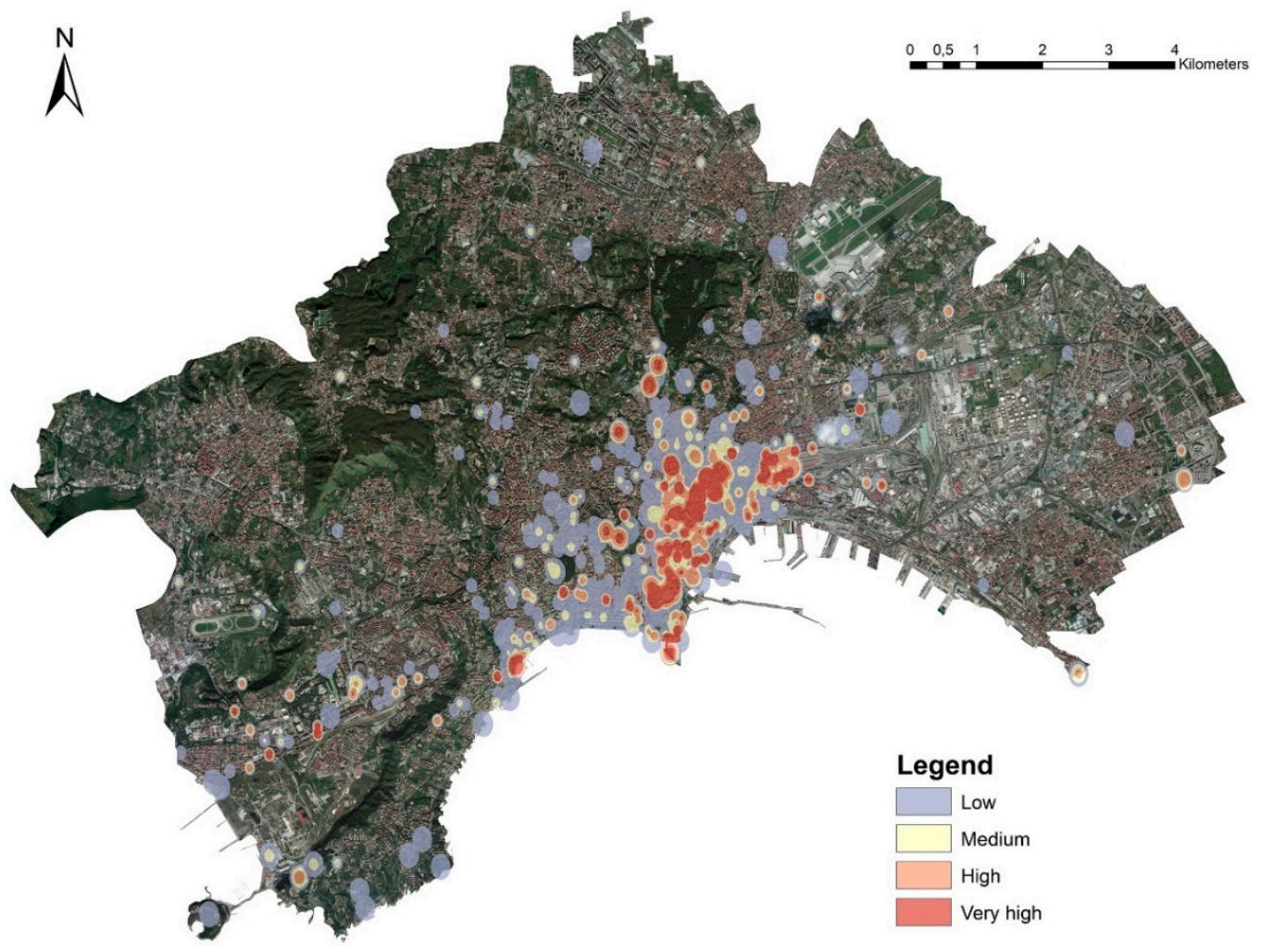

Figure 12. Polarization of tourism flows inside the tourist city of Naples. 


\section{Consideration of the Outcomes}

Kernel density estimation [58-62] is mostly used in spatial analysis to understand how events could distribute in a defined area. These methods are often applied to the definition of risk assessment or damage analysis, road accidents [63], and crime distribution [64-69]. Hot spots describing the density estimation show the intensity of the phenomenon in a certain location and some specific decisions can be taken regarding the interventions to control the impacts on the overall system concerned. Besides, spatial analysis is useful for describing relations between the three main urban subsystems and particularly among their elements (activities, spaces, and behaviors). When applied to tourism, spatial analysis is a useful means for studying phenomena that can affect urban equilibrium (even if it is connected to positive effects on local economies).

In the case shown, the "sensible urban areas" identified could be the object of a strategic plan for tourism in Naples that integrates the indications of an urban master plan for sustainable development, underlying the need to merge the objectives of traditional urban planning and the improvement of sustainable ways to live and visit a city. The present procedure, furthermore, has to be considered as an initial useful tool for managing and promoting tourism with respect to the characteristics of the urban system involved, and at the same time, it can act as a means for monitoring the efficiency of urban policies oriented towards the sustainable development of tourism.

\section{Conclusions and Further Research Developments}

This study represents a first attempt to ponder the transition era we are living in, thus advocating different mindsets and actions. Cities are the physical places where these changes are taking place, but at the same time, that is where answers can be found.

Technologies play a strategic role for both the development of the processes and for the improvement of cities' "smartness" in all their components.

The possibility of tracing the "urban agents" (residents, city users, tourists, commuters) has radically modified the relation between spaces and activities. This possibility can be a chance as well as a risk. Urban planning has its own responsibilities in this transition as it has called for a renewal of methods, approaches, and tools to obtain objectives of sustainability and to make cities efficient and livable.

The example of tourism refers to a phenomenon that is increasingly affecting cities, characterized by being a double-faced activity that, if not well-planned, can backfire on both the objectives of development and sustainability.

Considering tourist activities necessarily requires a wide availability of data and information. In this regard, the use of social media to collect data from people living and moving inside the city could be very useful in individuating those urban areas where action is urgently needed. The role of ICTs could be fundamental if they also referred to multiple contextualized transactions, not only information but also the context's description and impression. In this framework, residents, city users, and tourists can be thought of as "anthropic sensors," both sharing information in the functional space and describing phenomena occurring in the physical space. This is the meaning given to the UGC platform, such as TripAdvisor, in the context of this study.

What really ought to be pointed out is the exigency of being able to determine the correct use of technologies within the process of governance of the urban system. The major challenge, thus, is not the collection of data from web platforms, but rather the capability of converting them into useful tools for understanding the complexity of urban phenomena.

Further investigations shall be carried out to improve the subject of this study and to better explore the behaviors of urban populations [70].

Indeed, the analysis of tourist flows explored in the case study will need a deeper definition in order to strengthen the linkage between the theoretical baselines of the study and the effect of a complex urban function such as tourism. The starting point for further development of the proposed study could be oriented toward the study of the relationship between urban entropy and the concentration 
of users in areas of the city that, for their characteristics, play as "urban magnets" (namely they act as poles of attraction inside the urban system), and as such, they need particular attention in the management of the city, both to assure its efficiency and to achieve the city equilibrium.

The studies on destinations as open complex systems [71-73] demonstrate that it is possible to propose different from the usual paradigms to approach the theme of tourist destination [74]. In this study, it has been just suggested that the relationship between tourism and the city could open interesting perspectives in the field of urban planning, if tourism will be thought as an urban activity, and as such, the management of flows that it activates inside the city has to be one of the objectives of the present actions of urban governance.

Author Contributions: Even though the paper is the result of a authors' common research work, C.G. supervised the whole research project; R.F. developed the parts on the systemic approach and entropy of the complex systems; R.B. contributed to the analysis of the data and of the case study; and R.A.L.R. developed the parts on tourism activity, the elaboration of the case study, and assembled the paper.

Funding: This research received no external funding.

Conflicts of Interest: The authors declare no conflict of interest.

\section{References}

1. La Rocca, R.A. From sustainable city to smart city. In Towards Smart City. A Scientific Approach; Papa, R., Ed.; Aracne: Roma, Italy, 2014; pp. 199-207, ISBN 978-88-548-7024-6.

2. Giffinger, R.; Fertner, C.; Kramar, H.; Kalasek, R.; Pichler-Milanovic, N.; Meijers, E. Smart Cities. Ranking of European Medium-Sized Cities; Final Report; Centre of Regional Science: Vienna, UT, USA, 2007.

3. Caragliu, A.; Del Bo, C.; Nijkamp, P. Smart cities in Europe. J. Urban Technol. 2011, 18, 65-82. [CrossRef]

4. Papa, R.; Gargiulo, C.; Cristiano, M.; Di Francesco, I.; Tulisi, A. Less Smart More City. TeMA J. Land Use Mobil. Environ. 2015, 8, 159-182. [CrossRef]

5. Mora, L.; Bolici, R.; Deakin, M. The First Two Decades of Smart-City Research: A Bibliometric Analysis. J. Urban Technol. 2017, 24, 3-27. [CrossRef]

6. Ramaprasad, A.; Sánchez-Ortiz, A.; Syn, T. A Unified Definition of a Smart City. In 16th International Conference on Electronic Government (EGOV); Lecture Notes in Computer Science; Springer International Publishing: Berlin, Germany, 2017.

7. Azevedo Guedes, A.L.; Carvalho Alvarenga, J.; dos Santos Sgarbi Goulart, M.; Rodriguez, M.V.; Pereira Soares, C.A. Smart Cities: The Main Drivers for Increasing the Intelligence of Cities. Sustainability 2018, 10, 3121. [CrossRef]

8. Dall'O', G.; Sarto, L.; Panza, A.; Bruni, E.; Khayatian, F. Evaluation of cities' smartness by means of indicators for small and medium cities and communities: A methodology for Northern Italy. Sustain. Cities Soc. 2017, 34, 193-202. [CrossRef]

9. Gargiulo, C.; Battarra, R.; Pappalardo, G.; Boiano, A.D.; Oliva, J.S. Planning in the Era of Information and Communication Technologies. Discussing the "label: Smart" in South-European cities with environmental and socio-economic challenges. Cities 2016, 59, 1-7.

10. Papa, R.; Fistola, R. (Eds.) Smart Energy in the Smart City; Springer, Green Energy and Technology: Berlin, Germany, 2016.

11. Gargiulo, C.; Papa, R. Caos e caos: La città come fenomeno complesso. In Per il XXI Secolo: Una Enciclopedia e un Progetto; Beguinot, C., Ed.; Università degli Studi di Napoli Federico II: Napoli, Italy, 1993; pp. $297-306$.

12. Ashby, W.R. Introduction to Cybernetics; Chapman \& Hall: London, UK, 1956.

13. Von Bertalanffy, L. General System Theory. Foundations, Development, Applications; George Braziller: New York, NY, USA, 1968.

14. Mc Loughlin, J.B. Urban and Regional Planning. A Systems Approach; Faber and Faber: London, UK, 1969.

15. Wilson, A.; Bertuglia, C.S.; Leonardi, G.; Occelli, S.; Rabino, G.A.; Tadei, R. (Eds.) Urban Systems: Contemporary Approach to Modelling; Croom Helm: London, UK, 1987.

16. Nijkamp, P.; Reggiani, A. (Eds.) Nonlinear Evolution of Spatial Economic Systems; Springer: Berlin, Germany, 1993.

17. Allen, P.M. Cities and Regions as Self-Organizing Systems. Models of Complexity; Gordon and Breach: London, UK, 1997. 
18. Batty, M. Cities and Complexity: Understanding Cities with Cellular Automata, Agent-Based Models and Fractals; The MIT Press: Cambridge, MA, USA, 2005.

19. Fistola, R.; La Rocca, R.A. Smart City Planning: A systemic approach. In Establishing Bridges, Proceedings of the 6th Knowledge Cities World Summit (KCWS-2013), Istanbul, Turkey, 9-13 September 2013; Yiğitcanlar, T., Bulu, M., Eds.; Lookus Scientific: Istanbul, Turkey, 2013.

20. Fistola, R. Urban entropy vs sustainability: A new town planning perspective. In The Sustainable City VII; Pacetti, M., Passerini, G., Brebbia, C.A., Latini, G., Eds.; WIT Press: Southampton, UK, 2012; Volume 155, pp. 185-204.

21. Carnot, S. Reflections on the Motive Power of Fire; Manchester University Press: Manchester UK, 2012.

22. Rifkin, J.; Howard, T. Entropy: A New World View; Viking Press: New York, NY, USA, 1980.

23. Ben-Naim, A. Entropy Demystified. The Second Law Reduced to Plain Common Sense; World Scientific Publishing Co. Pte. Ltd.: Singapore, 2008.

24. Silvestrini, V. Che cosa è l'entropia. Ordine, disordine, evoluzione dei sistemi; Editori Riuniti University Press: Roma, Italy, 2012.

25. Prigogine, I.; Nicolis, G. La complessità. Esplorazioni nei nuovi campi della scienza; Einaudi: Torino, Italy, 1991.

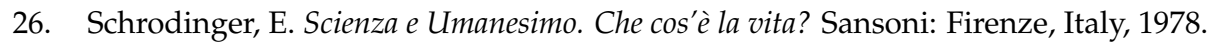

27. Xue, F.; Guo, L.; Huang, M.Y. Towards understanding the capability of adaptation for time-varying systems. Automatica 2001, 37, 1551-1560. [CrossRef]

28. Benveniste, A. Design of adaptive algorithms for the tracking of time-varying systems. Int. J. Adapt. Control Signal Process. 1987, 1, 3-29. [CrossRef]

29. Millnert, M. Identification of ARX models with Markovian parameters. Int. J. Control 1987, 45, $2045-2058$. [CrossRef]

30. Braithwaite, I.; Stewart, A.W.; Hancox, R.J.; Beasley, R.; Murphy, R.; Mitchell, E.A.; ISAAC Phase Three Study Group. The Worldwide Association between Television Viewing and Obesity in Children and Adolescents: Cross Sectional Study. PLoS ONE 2013, 8, e74263. [CrossRef]

31. De Souza Bispo, M. Tourism as practice: Humans and non-humans constructing an organizational texture of 'tourisming'. Turismo Desenvolvimento 2014, 5, 21-22.

32. Pearce, P.L. Tourist Behaviour: Themes and Conceptual Schemes; Aspect of Tourism: 27; The Cromwell Press: Trowbridge, UK, 2005.

33. Enright, M.J.; Newton, J. Tourism destination competitiveness: A quantitative approach. Tour. Manag. 2004, 25, 777-788. [CrossRef]

34. Ashworth, G.; Page, S.J. Urban tourism research: Recent progress and current paradoxes. Tour. Manag. 2011, 32, 1-15. [CrossRef]

35. UNWTO. World Tourism Barometer. Available online: http://marketintelligence.unwto.org/content/ unwto-world-tourism-barometer (accessed on 14 February 2019).

36. Pearce, D.G. An integrative framework for urban tourism research. Ann. Tour. Res. 2001, 28, 926-946. [CrossRef]

37. Evans, G. Planning for Urban Tourism: A Critique of Borough Development Plans and Tourism Policy in London. Int. J. Tour. Res. 2000, 2, 307-326. [CrossRef]

38. Fistola, R.; La Rocca, R.A. Driving functions for urban sustainability: The double-edged nature of urban tourism. Int. J. Sustain. Dev. Plan. 2017, 12, 425-434. [CrossRef]

39. La Rocca, R.A. The Role of Tourism in Planning the Smart City. TeMA J. Land Use Mobil. Environ. 2014, 7, 269-283. [CrossRef]

40. Koens, K.; Postma, A.; Papp, B. Is Overtourism Overused? Understanding the Impact of Tourism in a City Context. Sustainability 2018, 10, 4384. [CrossRef]

41. Pearce, D. Tourism development in Paris: Public intervention. Ann. Tour. Res. 1998, 25, 457-476. [CrossRef]

42. Van der Borg, J. Tourism management and carrying capacity in heritage cities and sites. In The Challenge of Tourism Carrying Capacity Assessment: Theory and Practice; Coccossis, H., Mexa, A., Eds.; Routledge: Wallingford, UK, 2004; pp. 163-179.

43. Pearce, D.G. Tourist districts in Paris: Structure and functions. Tour. Manag. 1998, 19, 49-65. [CrossRef]

44. Duhamel, P.; Knafou, R. Le tourisme dans la centralité parisienne. In La Métropole Parisienne. Centralités, Inégalités, Proximités; Saint-Julien, T., Le Goix, R., Eds.; Mappemonde: Paris, France, 2007; pp. 39-64. 
45. Douglas, G.; Pearce, S.J. Urban management, destination management and urban destination management: A comparative review with issues and examples from New Zealand. Int. J. Tour. Cities 2015, 1, 1-17. [CrossRef]

46. La Rocca, R.A. Turismo Turismi e Città. Una proposta di Piano di Sviluppo Turistico per Napoli; Collana Di.Pi.S.T.-Sezione Giovani Ricercatori e Dottorato di Ricerca; Giannini Editore: Napoli, Italy, 2003.

47. Cisco Visual Networking Index: Global Mobile Data Traffic Forecast Update, 2016-2021. Available online: www.cisco.com (accessed on 3 January 2017).

48. Custom Survey Research Engagement. Available online: https://www.phocuswright.com (accessed on 30 December 2016).

49. Park, Y.; Gretzel, U.; Sirakaya-Turk, E. Measuring web site quality for online travel agencies. J. Travel Tour. Mark. 2007, 23, 15-30. [CrossRef]

50. Borruso, G. Network density estimation: A GIS approach for analysing point patterns in a network space. Trans. GIS 2008, 12, 377-402. [CrossRef]

51. O'sullivan, D.; Unwin, D. Geographic Information Analysis; John Wiley Sons: New York, NY, USA, 2002.

52. Judd, D.R. The Infrastructure of the Play. Building the Tourist City; Cleveland State University: Cleveland, $\mathrm{OH}$, USA, 2003.

53. ISTAT (Italian National Institute of Statistics). Tourism Statistics. 2018. Available online: http://www.istat.it (accessed on 14 February 2019).

54. Sigala, M.; Gretzel, U. Advances in social media for travel. In Tourism and Hospitality: New Perspectives, Practice and Cases; Routledge: Abingdon, UK, 2018.

55. Sigala, M. New technologies in tourism: From multi-disciplinary to anti-disciplinary advances and trajectories. Tour. Manag. Perspect. 2018, 25, 151-155. [CrossRef]

56. Gretzel, U.; Sigala, M.; Xiang, Z.; Koo, C. Smart tourism: Foundations and developments. Electron. Mark. 2015, 25, 179-188. [CrossRef]

57. Venables, W.N.; Ripley, B.D. Modern Applied Statistics with S; Springer: Berlin, Germany, 2002.

58. Guidoum, A.C. Kernel Estimator and Bandwidth Selection for Density and its Derivatives. 2015. Available online: https://www.researchgate.net/publication/283573897_Kernel_estimator_and_ bandwidth_selection_for_density_and_its_derivatives (accessed on 14 February 2019).

59. Hart, T.; Zandbergen, P. Kernel density estimation and hotspot mapping: Examining the influence of interpolation method, grid cell size, and bandwidth on crime forecasting. Polic. Int. J. Police Strateg. Manag. 2014, 37, 305-323. [CrossRef]

60. Getis, A.; Ord, J.-K. Local spatial statistics: An overview. In Spatial Analysis: Modelling in a GIS Environment; Longley, P., Batty, M., Eds.; John Wiley \& Sons: New York, NY, USA, 1996; pp. 261-282.

61. Turlach, B.A. Bandwidth Selection in Kernel Density Estimation: A Review; CORE and Institut de Statistique. Université Catholique de Louvain: Louvain-laNeuve, Belgium, 1993.

62. Silverman, B.W. Density estimation for statistics and data analysis. In Monographs on Statistics and Applied Probability; Chapman and Hall: London, UK, 1986.

63. Anderson, T.K. Kernel density estimation and K-means clustering to profile road accident hotspots. Accid. Anal. Prev. 2009, 41, 359-364. [CrossRef]

64. Chainey, S.; Ratcliffe, J.H. GIS and Crime Mapping; Wiley: London, UK, 2005.

65. Ratcliffe, J. Crime mapping: Spatial and temporal challenges. In Handbook of Quantitative Criminology; Springer: New York, NY, USA, 2010.

66. Bruce, C.W.; Smith, S.C. Spatial Statistics in Crime Analysis; International Association of Crime Analysts: Overland Park, KS, USA, 2011.

67. Rey, S.J.; Mack, E.A.; Koschinsky, J. Exploratory Space-time analysis of Burglary Patterns. J. Quant. Criminol. 2012, 28, 509-553. [CrossRef]

68. Mburu, L.; Zipf, A. A Spatial Approach to Surveying Crime-Problematic Areas at the Street Level. In Proceedings of the Agile 2014 International Conference on Geographic Information Science, Castellón, Spain, 3-16 June 2014.

69. Levine, N. CrimeStat: A Spatial Statistical Program for the Analysis of Crime Incidents. In Encyclopedia of GIS; Shekhar, S., Xiong, H., Zhou, X., Eds.; Springer: Berlin, Germany, 2017.

70. Martinotti, G. Metropoli. La Nuova Morfologia Sociale della Città; Il Mulino: Bologna, Italy, 1993.

71. Beritelli, P.; Bieger, T.; Laesser, C. The New Frontiers of Destination Management: Applying Variable Geometry as a Function-Based Approach. J. Travel Res. 2014, 53, 403-417. [CrossRef] 
72. Baggio, R. Studying complex tourism systems: A novel approach based on networks derived from time series. In Proceedings of the XIV April International Academic Conference on Economic and Social Development, Moscow, Russia, 2-5 April 2013.

73. Jakulin Jere, T. Systems approach to tourism: A methodology for defining complex tourism system. Organizacija 2017, 50, 208-215. [CrossRef]

74. La Rocca, R.A. Tourism and Mobility. Best Practices and Conditions to Improve Urban Livability. TeMA J. Land Use Mobil. Environ. 2015, 8, 311-330. [CrossRef]

(C) 2019 by the authors. Licensee MDPI, Basel, Switzerland. This article is an open access article distributed under the terms and conditions of the Creative Commons Attribution (CC BY) license (http:/ / creativecommons.org/licenses/by/4.0/). 